\title{
On Relation between Sheep Horn Bell and Ancient Guangxi Musical Culture
}

\author{
Zhian Bie \\ Normal College \\ Nanyang Institute of Technology \\ Nanyang, China
}

\begin{abstract}
The Sheep Horn-bell was a representative implement in bronze culture in southeast area in ancient China, an old national musical instrument and sacrificial vessel rich in local features. It can be seen from the unearthing range and number that the Sheep Horn-bell was a representative ritual and music object in Luoyue nationality in ancient Guangxi, and we can understand its special status in Luoyue nationality by observing it and other contemporary bronze musical instrument.
\end{abstract}

Keywords-sheep horn bell; bronze culture; Guangxi; music of Luoyue nationality

\section{INTRODUCTION}

The Sheep Horn-bell was a representative implement in bronze culture in southeast area in ancient China, an old national musical instrument and sacrificial vessel rich in local features. According to known unearthing data, it rose from the Warring States to early Western Han Dynasty and gradually perished in Eastern Han Dynasty. $t$ was only discovered in southern area, and it was not seen in record of inscriptions on ancient bronzes and stone tablets in past dynasties. Researcher Jiang Tingyu, Guangxi archaeologist named it "Sheep Hornbell" according to its form and it was accepted by the academic circle. Study and research on Sheep Horn-bell help us perceive the special object and culture of ritual and music during the period when minorities of Lingnan and southwest area marched toward kingdom culture. In this paper, the author conducts comprehensive research and investigation on the Sheep Horn-bell and the unearthed contemporary ritual and music object, and discusses the interrelation between the Sheep Horn-bell and other ritual and music object of Luoyue nationality in ancient Guangxi and its historical status.

\section{THE SHEEP HORN-BELL WAS A REPRESENTATIVE RITUAL AND MUSIC OBJECT OF LUOYUE NATIONALITY IN ANCIENT GUANGXI}

Guangxi has abundant resource of music of the minority nationalities, which is praised as hometown of "Song Ocean". Guangxi also has special and abundant resource of historical music. As early as more than 50 thousand years ago, ancestors of Zhuang nationality lived in this area; to Shang, Zhou and pre-Qin period, Guangxi was called "Xiou", "Luoyue" and "Cangwu", and developed from ancient state to kingdom culture, and created special culture and civilization, whose symbol was the development of special local bronze culture; in late Qin and early Han, Qin general Zhao Tuo built Nanyue state, to which most part of Guangxi belonged, speeding up the civilization of Guangxi; up to the reign of Emperor Wu of Han, as the power of the Central Plains went southward, Guangxi entered the feudal society, and the mainstream culture was also unified into the great Chinese system; after Wei and Jin Dynasties, ancient tribe of Guangxi gradually developed to abundant minority tribes as it is today. Thus, the history of music culture of Guangxi in ancient times had a certain relation to music culture of the Central Plains and Chu area, but it presented different styles and features more. In brief, effected by the rite and music culture of the Central Plains and $\mathrm{Chu}$ area, and in the communication with kingdoms of Yue nationality in southwest area which developed to kingdom culture along with the western area, ancestors of Zhuang nationality also generated rite and music culture with local features and national style, whose material carrier mainly reflected in the ritual and music object in archaeological discovery.

So far the author has mastered the data that as far as Guangxi area is concerned, ever since the 1960 s, totally 24 objects have been found in scientific excavation and sporadic discovery in 11 places, which include the lost bells whose whereabouts is unknown (Pubei Lizhukui Bell, 3 unearthed, 2 lost); 23 objects have been found in 9 places in Yunnan (2 objects' whereabouts are unknown); 2 objects have been found in 2 places in Guizhou, 5 in Hunan (belong to collection), 1 in Guangzhou, 14 in Vietnam. Thus, Guangxi is the area where most Sheep Horn-bells have been found so far. The detail is as follow:

- Guigang Bell. It was unearthed in Guigang (formerly called as Gui County), Guangxi, $23.3 \mathrm{~cm}$ high, and the bottom diameter was $15.0 \mathrm{~cm}$ long, $9.5 \mathrm{~cm}$ broad. It is now collected in Guangxi Museum.[1]

- Xilin Putuo Bell. In 1972.7, farmers of Putuo Village, Puhe Brigade, Bada Commune, Xilin County, Guangxi found an ancient tomb taking bronze drum as funerary utensil when expanding the grain-sunning ground, and unearthed a batch of precious cultural relic, including 2 Sheep Horn-bells with similar shapes and sizes, plain end, plain surface, a rectangular hole penetrates the top, which is decorated with two pieces of sheep-horn handles. It was $28 \mathrm{~cm}$ high, and the bottom diameter 
was $17.6 \mathrm{~cm}$ long and $12.7 \mathrm{~cm}$ broad. Many bird feathers were stuck to the green embroidery. The period was early Western Han Dynasty.[2]

- Pubei Dajiaoling Bell. In 1974, 4 bells were unearthed in Houbei Hill, Dalingjiao Village, Pingshi Brigade, Guantong Commune, Pubei County, Guangxi. It is still unknown whether there is other subject. The 4 objects have similar sizes, $25 \mathrm{~cm}$ high, and the bottom diameter was $15.2 \mathrm{~cm}$ long and $9.7 \mathrm{~cm}$ broad, there is a rhombic thunder pattern at the bottom. The period was Han Dynasty. It is now collected in Pubei Museum.[3]

- Rong County Longjinghua Bell. 4 Sheep Horn-bells were unearthed in Longjinghua, Liuwang Commune, Rong County in 1976, whose unearthing condition was unknown. There was a little difference among the shapes and sizes of the four bells, whose shape was like a half olive, a little slender, big on the top and small on the bottom, hollow in the middle, plain end. There were two sheep horn handles with vertical rectangular holes. The face was decorated with cloud patterns, and the lower part was decorated with dense bow string pattern, like bronze drum. One of them (Rong**long No.1) had a reverse eight-shaped handle pattern on the top, $22.8 \mathrm{~cm}$ high. The rest 3 objects had two pieces handles pulled into line on the top, $20.4-20.5 \mathrm{~cm}$ high. The period was Warring States period and Western Han Dynasty.[4]

- Guigang Luobowan Bell. It was found in No.1 Tomb in Luobowan Han Tomb in Gui County (now Guigang City) in 1976.8. It was unearthed from the object pit under a coffin in No.1 Tomb, along with 2 bronze drums, 2 semi-ring-handle cylindrical bronze drums and other bronze wares. Its shape was like a half olive, a little slender, big on the top and small on the bottom, hollow in the middle, plain end. It had two reverse eight-shaped handles on the top with vertical rectangular hole. There was pattern of human face on the front side, whose eyes, nose and mouth could be seen indistinctly. It was $19 \mathrm{~cm}$ high, and the bottom diameter was $14 \mathrm{~cm}$ long and $8.1 \mathrm{~cm}$ broad. It was measured in the sound detection that the middle tone was \#C5-27 and side tone was E5-4. The period was early Western Han Dynasty.It is now collected in Guangxi Museum.[5]

- Liuzhou Dapu Bell. On 1982.2.10, staff of Liuzhou Museum selected one bell from Wulika Warehouse in local product company in Liuzhou, which was later verified to come from Dapu Town, Liucheng County. There was a hole on one side of the bell with no pattern. It was $20.4 \mathrm{~cm}$ high, and the bottom diameter was $14 \mathrm{~cm}$ long, weighing $0.6 \mathrm{~kg}$. It is now collected in Liuzhou Museum.[6]

- Gongcheng County Dongzhai Bell. In 1984.3, farmer Liu Houcang in Dongzhai Village, Lianhua Town, Gongcheng County, Guangxi dug a bell in his own garden. It was made of bronze with casting trace on the two sides. Its cross section was in the shape of olive, big on the top and small on the bottom, hollow in the middle, plain end. There was two broken sheep horn handles on the top with vertical rectangular hole. The bell and inner wall were smooth with no pattern. It was $24.5 \mathrm{~cm}$ high, and the bottom diameter was $14 \mathrm{~cm}$ long and $8.1 \mathrm{~cm}$ broad, and the hole was $4.5 \mathrm{~cm}$ high, $1.5 \mathrm{~cm}$ broad, weighing $350 \mathrm{~g}$. The period was Western Han Dynasty. It is now collected in Gongcheng Museum in Guangxi.[7]

- Pubei Printing House Bell. In 1984 two bells were dug from the Printing House in Pubei County. One was $26.6 \mathrm{~cm}$ high, and the bottom diameter was $16.4 \mathrm{~cm}$ broad, whose front and back sides were both intaglio with patterns of figure and giant beast similar to the cliff painting in Zuojiang Basin. The other was broken. They are now collected in Pubei Museum.[8]

- Pubei Houbeiling Bell. In 1986 three bells were unearthed from Houbeiling, Liuliao Village, Fuwang Town, Pubei County, two of which were lost, and the other one is collected in Pubei Museum. It was $19.2 \mathrm{~cm}$ high and the bottom was $12.2 \mathrm{~cm}$ long.[9]

- Yulin Long'an Bell. In 2001, Yunlin Museum collected a Sheep Horn-bell in Han Dynasty. It was found in the field of cassava in Yangtang Village, Long'an Town by a farmer from Ganpo Village, Long'an Town, Xingye County. It was made of bronze, $22.61 \mathrm{~cm}$ high, and the bottom diameter was $14.2 \mathrm{~cm}$ long and $8.4 \mathrm{~cm}$ broad, with plain surface and no pattern. Its shape was like a half olive, a little slender, big on the top and small on the bottom, hollow in the middle, no bottom, the bottom margin was straight, and the cross section was also in the shape of olive. There was a rectangular hole penetrating the top, whose left and right sides were decorated with two handles in the shape of sheep horn. [10]

As per number or sequencing, Guangxi owns the largest unearthing number, whose sequencing was mainly in groups of 2 or 4 , with the basic musical features of skeleton tone. Besides, many sacrificial vessels and ritual and music objects were unearthed in the relics of tombs. It can be concluded that the Sheep Horn-bell was the representative ritual and music object of in Luoyue nationality in ancient Guangxi.

\section{SHEEP HORN-BELL AND OTHER RITUAL AND MUSIC OBJECTS OF IN LUOYUE NATIONALITY}

In the time when the Sheep Horn-bell prevailed, the bronze drum and Yue-style Yong bell also rose. There was an obvious connection among them.

The areal distribution of the Sheep Horn-bell was roughly consistent with the central area of distribution of ancient bronze drum. The patterns of some Sheep Horn bells were the same as the one of bronze drums, and in many tombs the Sheep Horn-bells and bronze drums appeared together, which were enough to show that the Sheep Horn-bell and bronze drum were "twins". At the same time, archaeologists also found that Sheep Horn-bells unearthed in different regions had different patterns, but they remained consistent with the locally 
unearthed bronze drums, which made it seem that the regional disparity of the Sheep Horn-bell was obvious. As far as the areal distribution of the Sheep Horn-bell was concerned, it was the central area of distribution of ancient bronze drums. As far as the pattern was concerned, the pattern of the Sheep Hornbell was similar to the bronze drum. For example, the Sheep Horn-bell unearthed in Rong County had S-type cloud pattern similar to bronze drum; the urine pattern on the bells in north Vietnam and the rhombic thunder pattern and dancing figure patter on the Sheep Horn-bells in Pubei were all normal patterns on bronze drums[12]. As far as the unearthing condition was concerned, the Sheep Horn-bell mostly arose along with bronze drums in ancient tombs with certain scale, which were owned by the nobility. For example, Yunnan Shizhaishan M6 where the golden snake-handle seal, "seal of King of Dian", jade burial suit and cylinder-shaped bronze chime with dragon pattern were unearthed was the tomb of King of Dian, and there was one Sheep Horn-bell and two bronze drums among the burial objects; the two sheep horn bronze bells in Putuo, Xilin, Guangxi were from the tomb of bronze drums surrounded by four sides of bronze drums with abundant burial objects, whose master might be the leader of ancient Juting state; Gui County Luobowan M1 was a large tomb of the highest official of Guilin County during the period of Nanyue State, which had nearly one thousand burial objects, including one Sheep Horn-bell, a pair of semi-ring bells, two "male and female" bronze drums and one gongs. The Sheep Horn-bell and the bronze drum created the music of bronze drum and the rites and music culture of Guangxi in ancient times together.

Lingnan Yong Bell was popular before Qin unified Lingnan. Many Han tombs were dug in Lingnan area, among which only the tomb of Nanyue king of Western Han contained Yong bells, and there was no unearth tomb which contained both the Sheep Horn-bell and Yue-style Yong bell. The author thinks that Yue-style Yong bell and the Sheep Horn-bell were the product of combination between the culture of the Central Plains and local culture, only the First Emperor of Qin unified Lingnan earlier and Han set counties in southwest area and Guilin County in Nanyue State later, thus, the southeast part of Guangxi was influenced by the culture of the Central Plains earlier than the northwest part, which were exactly the two areas where Yue-style Yong bell and Sheep Horn-bell started. The Yue-style Yong bell went northward and the Sheep Horn-bell southward, which failed to spread along the original route because their owners collided with each other on national culture in the middle area of Guangxi. Thus Mr. Jiang Tingyu said that "There was Sheep Horn-bell but no Yong Bell in No.1 Han Tomb in Luobowan, Guangxi and bronze drum tomb of Western Han in Putuo, Xilin. There was Yong bell but no Sheep Horn-bell in tombs in Gongcheng, Qingyuan, Luoding and Zhaoqing, even including the tomb of Nanyue king in Guangzhou."[13] Mr. Jiang also thought that Yong bell and Sheep Horn-bell coexisted with each other in middle, north and southeast Guangxi, but Yong bell was popular earlier than the Sheep Horn-bell, more precisely, Yong bell of Yue nationality disappeared in early Western Han Dynasty.[14]

\section{RituAl AND MUSiCAl FunCTION OF SHEEP HORN BELL}

Authorities dug five Yong bells and one Juzheng in Tomb 1 in Matonggang, Qingyuan, and dug six Yong bells and one Juzheng in Tomb 1 in Nanmeng, Luoding. Five Yong bells, eight Juzheng, fourteen handle bells, eighteen stone chime were dug from the tomb of Emperor Wen of Nanyue in Guangzhou, among which the chime and Juzheng were confirmed to use heptachord, "one bell with double tone"[15] after complete detection. If the sound of the bronze musical instrument unearthed in Lingnan is detected, we will have more complete understanding to this issue. At present, the work is ongoing, and maybe we can listen to the beautiful sound from the imitation of these unearthed musical instrument soon after.

Coincidentally, there was one Sheep Horn-bell, 2 semi-ring handle bells, one bronze drum and one bronze gong among the unearthed historical relics in Han Tomb 1 in Luobowan, Gui County, Guangxi, and there were 2 bamboo flutes in the coffin of those buried alive with the dead. According to preliminary analysis, this was a set of bell and drum dominated by bronze chime and bronze drum. According to the sound after sound detection, the bamboo flute might be the main musical instrument among this set and played the main melody. Guangxi archaeologist Mr. Jiang Tingyu boldly speculated that the Sheep Horn-bell, semi-ring handle bell and bronze drum played skeleton music or summation tone consisting of different intervals accompanied, two semi-ring handle bells and bronze drum played on the same octave at the same time, the semi-ring handle bell played la and do of $\mathrm{E}$, the bronze drum played do and mi of E, the Sheep Horn-bell played la and do on its octave. Thus the chord was formed, accompanying the main melody, setting it off. Mr. Jiang Tingyu analyzed that the semi-ring handle bell and bronze gong unearthed in Han Tomb 1 in Luobowan, Gui County, Guangxi were both carved with the character "Bu", which should be the abbreviation of "Bushan". Bushan was a county town in Guilin County in Qin and Western Han, namely Gui County today (changed its name into Guigang City in 1989). Bronze bells and bronze gongs with the inscription "Bu" should be local musical instrument in Bushan, do of E made by which should represent the pitch standard of Bushan area. There was no inscription on the Sheep Horn-bell unearthed from the same tomb, but its pitch was fully consistent with that of the bells and gongs with inscription of "Bu" and was quite correct, so it shall also belong to local musical instrument of Bushan. The pitch of Bushan represented by bells and gongs with inscription of "Bu" might be the inheritance and development of the pitch of Yue-style bronze Yong bell in Guangxi during the Warring States period; Spring and Autumn Period. [16]

The above analysis shows the inheritance and development between Yue-style Yong bell and Sheep Horn-bell. In China's slave society, bell was a symbol of certain status and hierarchy, so were Sheep Horn-bell and bronze drum, which reflected that Lingnan area had been authentic class society during the Warring States period ; Spring and Autumn Period. The bronze drum music consisting of Sheep Horn-bell and bronze drum was one of the symbols of development of rite and music culture of Guangxi, which reflected that Sheep Horn-bell and 
bronze drum music were not folk music but music of the nobility in royal or imperial court. It was only used in worship ceremony and celebration of the nobility, and was the symbol of status and hierarchy of the local governors.

\section{REFERENCES}

[1] Yuan Huatao. Research on several issues of Sheep Horn-bell [D].2007

[2] Archaeological Team of Guangxi Zhuang Autonomous Region. Tomb of Bronze Drum in Putuo, Xilin County, Guangxi [J]. Relic, 1978 (9).

[3] Jiang Tingyu. First Analysis of bronze Sheep Horn-bell [J]. Relic, 1984 (5).

[4] Ditto.

[5] Archaeological Team of Guangxi Zhuang Autonomous Region. Brief report of excavation of Tomb 1 in Luobowan, Gui County, Guangxi [J]. Relic, 1978 (9).

[6] Jiang Tingyu. Bronze Sheep Horn-bell [J]. Culture of Palace Museum (Taiwan). 2001 (2).

[7] Feng Yan. One Han bronze Sheep Horn-bell was found in Dongzhai Village, Gongcheng County, Guangxi [J]. Guangxi Relic, 1988 (1).

[8] The same as [6].

[9] The same as [3].

[10] Guangxi almanac, 2002, page 468.

[11] Material offered by Jiang Tingyu.

[12] Zhang Rongfang, Haung Miaozhang, History of Nanyue State [M]. Guangdong People's publishing House, 1995.12, first edition

[13] Jiang Tingyu. Brief discussion on bronze bell in Lingnan [J]. Jiangxi Relic, 1989 (1)

[14] Ditto.

[15] Kong Yilong, Liu Chengji. Collection II of China's music heritage (Guangdong volume) [M]. Zhengzhou: Daxiang Press House, 2010.

[16] Jiang Tingyu. Supplement to bronze Sheep Horn-bell [J]. Study of Nationalities in Guangxi, 1989 (4). 